\title{
Resposta do feijoeiro a lâminas de água aplicada em relação à evapotranspiração da cultura ${ }^{1}$
}

\author{
Dayane Mércia Ribeiro Silva ${ }^{2}$, Jania Claudia Camilo dos Santos ${ }^{2}$, Renato Nunes Costa ${ }^{3}$, Alex Oliveira \\ Rocha $^{4}$, Ana Nathaly da Silva Lima ${ }^{5}$, Saymon Acchile Santos ${ }^{4}$, Lennon Kledson dos Santos Silva ${ }^{2}$
}

\author{
${ }^{1}$ Submetido em 17-03-2017 e aprovado em 27-04-2017 \\ ${ }^{2}$ Mestrado em Agronomia, Universidade Federal de Alagoas, Arapiraca - AL, CEP:57309-005; e-mail: \\ dayannemercia@hotmail.com; janya-claudia@hotmail.com; kledson.lennon@hotmail.com \\ ${ }^{3}$ Doutorando em Agronomia, Universidade Estadual Paulista, Botucatu - SP, CEP: 18610-307; e-mail: \\ renatonunes12@hotmail.com \\ ${ }^{4}$ Mestrando em Proteção de Plantas, Universidade Federal de Alagoas, Maceió -AL, CEP:57072-900; e-mail: \\ alex_touro@msn.com; saymonufal@gmail.com \\ ${ }^{5}$ Graduada em Agronomia, Universidade Federal de Alagoas, Arapiraca-AL, CEP:57309-005; e-mail: \\ nathaly_s117@hotmail.com
}

\begin{abstract}
Resumo - No Brasil, o feijão é um dos principais alimentos básicos da população devido elevado potencial energético, destacando-se tanto na produção para subsistência quanto para a agricultura empresarial, por ser uma cultura sensível ao déficit ou excesso de água no solo. Objetivou-se avaliar diferentes lâminas de água aplicada à cultura do feijoeiro em relação à evapotranspiração da cultura. O experimento foi conduzido em área pertencente à Universidade Federal de Alagoas/Campus Arapiraca, em condições de campo, durante o período de Agosto a Novembro de 2016, utilizando a cultivar carioca, com densidade de plantas de 240 mil por hectare. Foram analisadas as lâminas de água de acordo com a evapotranspiração da cultura, em cinco níveis de água $(25,50,75$, $100,125 \%$ ). Foram avaliadas área foliar, diâmetro do caule, comprimento do caule, número de vagens por planta, comprimento da vagem e largura da vagem. Os dados foram submetidos a análises de variância e regressão, utilizando o teste $\mathrm{F}(\mathrm{p} \leq 0,05)$ para verificar a significância. A partir da análise de variância constatou-se diferença significativa entre os tratamentos em todas as variáveis analisadas. Constatou-se que os níveis de irrigação inferiores a $100 \%$ da evapotranspiração da cultura afetaram negativamente as variáveis analisadas, inibindo o crescimento, com maior intensidade na área foliar e no número de vagem.
\end{abstract}

Palavras-chave: Phaseolus vulgaris L.; Déficit hídrico; Morfologia; Características agronômicas.

\section{Response of common bean to applied water sheets in relation to crop evapotranspiration}

\begin{abstract}
In Brazil, beans are one of the main staple foods of the population due to high energy potential, standing out in both subsistence production and business agriculture, because it is a crop sensitive to the deficit or excess of water in the soil. The objective of this study was to evaluate the different water sheets applied to the bean crop in relation to crop evapotranspiration. The experiment was conducted in an area belonging to the Federal University of Alagoas/Arapiraca Campus, under field conditions, during the period from August to November 2016, using the cultivar carioca, with plant density of 240 thousand per hectare. Water slides were analyzed according to crop evapotranspiration at five water levels $(25,50,75,100,125 \%)$. Leaf area, stem diameter, stem length, number of pods per plant, pod length and pod width were evaluated. The data were submitted to analysis of variance and regression using the $\mathrm{F}$ test $(\mathrm{p} \leq 0.05)$ to verify the significance. From the analysis of variance it was verified a significant difference between the treatments in all variables analyzed. Irrigation levels below $100 \%$ of crop evapotranspiration negatively affected the analyzed variables, inhibiting growth, with greater intensity in the leaf area and in the number of pods.
\end{abstract}

Keywords: Phaseolus vulgaris L.; Water deficit; Morphology; Agronomic characteristics.

Revista Agropecuária Técnica, Areia-PB, v. 38, n. 2, p. 71-77, 2017

DOI: 10.25066 /agrotec.v38i2.33362 


\section{Introdução}

O feijoeiro (Phaseolus vulgaris) é uma das principais culturas cultivadas no Brasil, produtiva durante todo o ano em diferentes condições edafoclimáticas, sem restrições durante o desenvolvimento da planta (SIMPLÍCIO et al., 2016; SILVA et al., 2017). O maior País produtor mundial de feijão-comum é o Brasil, estando em segundo lugar Minas Gerais com $15 \%$ da produção nacional; é importante ressaltar que a produção nacional gira em torno de 3,4 milhões de toneladas, com produtividade média de $852 \mathrm{~kg}$ $\mathrm{ha}^{-1}$, este valor quando comparado ao potencial produtivo das cultivares, ainda é considerado baixo (PAULA JÚNIOR et al., 2008; MARTINS et al., 2009).

Uma estratégia de manejo específica pode ser evidenciada pelos fatores físicos do solo que incluem $o$ teor de água, sistema de armazenamento, aeração e os impedimentos mecânicos presentes no solo os quais dificultam o desenvolvimento das raízes, e podem ser reduzidos pelo conhecimento dos atributos físicos do solo e das cultivares de feijão utilizada em busca de aperfeiçoar e melhorar a produtividade agrícola (CARVALHO et al., 2006; SILVA et al., 2017).

A influência do déficit hídrico sobre a cultura do feijoeiro ainda merece bastante atenção, tendo em vista que a redução da disponibilidade hídrica do solo, pode causar sérios prejuízos à cultura, principalmente durante o período veranico, causando implicações diretas ao desenvolvimento da planta nos processos fisiológicos, com redução da transpiração, taxa fotossintética, temperatura foliar e morfologia das plantas, prejudicando a produção em casos de secas severas (MENDES et al., 2007; SANTOS et al., 2009; PEIXOTO, 2011; FERNANDES et al., 2015).

Sabe-se que o produtor rural normalmente irriga em excesso, uma vez que teme o déficit hídrico da cultura, desse modo, a não utilização de um método adequado pode comprometer a produção (TURCO; RIZZATTI; PAVANI, 2009). Por isso, torna-se crucial o manejo hídrico mais adequado, que trará maiores produtividades com menores custos e forma sustentável (FREITAS et al., 2010). Neste sentido, a quantidade de água necessária para determinada cultura é um dado básico que deve ser conhecido para se planejar e praticar um manejo adequado de qualquer projeto de irrigação (SOARES et al., 2001).

Entretanto, a irrigação na região ainda necessita de estudos para manifestar sua total potencialidade, necessitando de melhor controle quanto à quantidade de água a ser aplicada, à frequência e ao momento crítico de irrigação (SOUSA et al., 2010). A cultivar carioca responde diferentemente às lâminas de água aplicada? Existem diferenças quanto ao desenvolvimento das características agronômicas de Phaseolus vulgaris na região? Para responder estas questões, neste trabalho foram avaliadas a resposta do feijoeiro sob lâminas de água aplicada em relação à evapotranspiração da cultura na região Agreste de Alagoas.

\section{Material e Métodos}

$\mathrm{O}$ experimento foi conduzido na área experimental da Universidade Federal de Alagoas-UFAL/Campus Arapiraca ( $9^{\circ} 41^{\prime} 53,6^{\prime \prime}$ S; 3641'26,3" O, 264 metros), na região Agreste Alagoana, em condições de campo, durante o período de Agosto a Novembro de 2016, utilizando o feijão Phaseolus vulgaris L., cultivar Carioca. O solo da área foi classificado como Argissolo Vermelho Distrófico, com textura areno-argiloso (EMBRAPA, 2006), e apresentaram as seguintes características químicas: $\mathrm{pH}$ (água) de 5,7 ; teor de matéria orgânica de $15 \mathrm{~g} \mathrm{dm}^{-3}$; saturação por base (V\%) de $43 \%$; $\mathrm{P}$ de $0,25 \mathrm{cmolc} \mathrm{dm}^{-3}$; $\mathrm{K}$ de 0,2 cmolc $\mathrm{dm}^{-3}$; Ca de 1,4 $\mathrm{cmolc} \mathrm{dm}^{-3} ; \mathrm{Mg}$ de $1,4 \mathrm{cmolc} \mathrm{dm}^{-}$ 3. Al de 0,2 $\mathrm{cmolc} \mathrm{dm}^{-3}$ e $\mathrm{H}+\mathrm{Al}$ de $4,0 \mathrm{cmolc} \mathrm{dm}^{-}$ 3 .

Foram semeadas 28 sementes por metro linear, sendo realizado o desbaste, 5 dias após a emergência, deixando 12 plantas espaçadas em 5 $\mathrm{cm}$. Deste modo, a densidade de semeadura foi de 560 mil sementes por hectare, e a densidade de plantas de 240 mil por hectare. Na adubação de fundação, foram aplicados: $20 \mathrm{~kg} \mathrm{ha}^{-1} \mathrm{de} \mathrm{N}, 30 \mathrm{~kg}$ $\mathrm{ha}^{-1}$ de P e $20 \mathrm{~kg} \mathrm{ha}^{-1}$ de K. Em cobertura foram aplicados $20 \mathrm{~kg} \mathrm{ha}^{-1}$ de $\mathrm{N}$ aos 30 dias após a emergência (DAE). Como fonte de $\mathrm{N}$ utilizou-se a Ureia, de P o Superfosfato Simples e de K o Cloreto de Potássio. Foram feitos controles fitossanitários para controle de formigas.

Adotou-se o delineamento em blocos casualizados com 5 tratamentos e 4 repetições. Os 
tratamentos consistiram-se nas lâminas de irrigação: $25 \%, 50 \%, 75 \%, 100 \%$ e $125 \%$ ETc (Evapotranspiração da Cultura). Dessa forma, para a determinação da ETP (Evapotranspiração Potencial ou real) utilizou o método HargreavesSamani um dos mais adequados para a região (PEREIRA et al., 2002), por atender satisfatoriamente as necessidades locais. Assim, a fórmula consiste em:

\section{$\mathrm{ETP}=0,0023$ Qo $(\text { Tmax }-\mathrm{Tmin})^{0,5}(\mathrm{Tmed}+17,8)$}

Em que:

$\mathrm{ETP}=$ Evapotranspiração Potencial (mm por dia);

Qo= Irradiância solar extraterrestre (mm por dia);

Tmáx= Temperatura máxima do $\operatorname{ar}\left({ }^{\circ} \mathrm{C}\right)$;

Tmin= Temperatura mínima do ar $\left({ }^{\circ} \mathrm{C}\right) ;$

Tméd = temperatura média do $\operatorname{ar}\left({ }^{\circ} \mathrm{C}\right)$.

Para a determinação da ETc utilizou-se a fórmula seguinte, onde os valores do Coeficiente da Cultura $(\mathrm{Kc})$ foram retirados de Manos et al. (2013). Sendo Kc de 0,69 da Germinação ao início da floração, de 1,28 durante a floração e 1,04 durante o desenvolvimento das vagens.

Assim, tem-se:

$\mathrm{ETc}=\mathrm{ETP}^{*} \mathrm{Kc}$.

Em que:

$\mathrm{ETc}=$ Evapotranspiração da Cultura (mm por dia);

$\mathrm{Kc}=$ Coeficiente da cultura.

A parcela foi constituída de 4 linhas com 1 metro de comprimento, com espaçamento entre linhas de $0,5 \mathrm{~m}$ e entre blocos, totalizando uma área de $66,5 \mathrm{~m}^{2}$. A área útil de cada parcela foi constituída de duas linhas centrais, desprezandose as duas linhas laterais para evitar o efeito bordadura.

Em relação aos índices biométricos, as análises de crescimento foram realizadas em 4 plantas de cada tratamento no $10^{\circ}$ dia após o plantio (DAP) e no final do ciclo da cultura, aos 84 DAP. Assim, foram aferidos: o comprimento do caule (CC), diâmetro do caule (DC), área foliar (AF), número de vagens por planta (NV), comprimento da vagem (CV) e largura da vagem (LV). Tais medições foram realizadas com o auxílio de régua e paquímetro analógico, já a área foliar foi medida através do medidor de área foliar (LI-3100, Li-Cor, Inc. Lincoln, NE, USA).

Os dados dos foram submetidos à análise de variância e regressão polinomial com o auxílio do programa estatístico SISVAR $^{\circledR}$ versão 5.3 Build 72 (FERREIRA, 2014) e as gráficos confeccionados através do software Microsoft Excel $^{\circledR}$.

\section{Resultados e Discussão}

A partir da análise de variância constatouse diferença significativa entre as lâminas de irrigação aplicada em todas as variáveis analisadas (Tabela 1), desse modo, ao décimo dia de avaliação a área foliar das plântulas do feijoeiro aumentou à medida que aumentaram a quantidade de água aplicada, que é justificado pelo aumento da taxa fotossintética em situações de maior disponibilidade hídrica no vegetal (GUIMARÃES; STONE; BRUNINI, 1996). Além disso, a redução da área foliar (Figura 1A) está relacionada com a redução do número de folhas que ocorre de acordo com a disponibilidade hídrica, como sendo uma estratégia de sobrevivência para as plantas, uma vez que reduz o número de folhas para que assim, ocorra diminuição da perda de água por transpiração, e consequentemente, redução da taxa fotossintética e menor crescimento (TAIZ; ZEIGER, 2013).

Ao estudarem o aparato fotossintético em plantas de feijão-caupi em situação de estresse hídrico, foi verificado que as plantas submetidas à reposição de $50 \%$ da água perdida por evapotranspiração não apresentam danos no aparelho fotossintético, enquanto que as plantas que recebem reposição de $25 \%$ da água perdida por evapotranspiração apresentam reduções nos níveis de assimilação fotossintética, condutância estomática e transpiração (SILVA et al., 2010). 
Tabela 1 Resumo da Análise de Variância para as variáveis área foliar (AF), diâmetro do caule (DC) e comprimento de caule (CC) aos 10 dias após a emergência (DAE) do feijoeiro e das variáveis número de vargens $(\mathrm{NV})$, comprimento do caule (CC), diâmetro do caule (DC), comprimento da vargem (CV) e largura da vargem (LV) aos 84 DAE em diferentes lâminas de irrigação.

\begin{tabular}{lcccc}
\hline \multirow{2}{*}{ Fontes de variação } & \multicolumn{4}{c}{ Quadrados médios } \\
\cline { 2 - 5 } & $\mathrm{AF}(10 \mathrm{DAE})$ & $\mathrm{DC}(10 \mathrm{DAE})$ & $\mathrm{CC}(10 \mathrm{DAE})$ & $\mathrm{NV}(84 \mathrm{DAE})$ \\
\hline Irrigação & $78,31^{*}$ & $0,55^{* *}$ & $1,10^{*}$ & $14,07^{* *}$ \\
Regressão Linear & $254,22^{*}$ & $1,60^{*}$ & $0,65^{* *}$ & $45,80^{*}$ \\
Regressão Quadrática & $3,89^{* *}$ & $0,29^{\mathrm{ns}}$ & $2,79^{*}$ & $5,28^{\mathrm{ns}}$ \\
Desvio Regressão & $27,56^{*}$ & $0,15^{\mathrm{ns}}$ & $0,48^{\mathrm{ns}}$ & $2,60^{\mathrm{ns}}$ \\
Bloco & $0,63^{\mathrm{ns}}$ & $0,11^{\mathrm{ns}}$ & $0,09^{\mathrm{ns}}$ & $10,26^{* *}$ \\
CV $(\%)$ & 5,68 & 9,34 & 17,23 & 15,74 \\
\hline \multicolumn{1}{c}{ Fontes de variação } & \multicolumn{4}{c}{ Quadrados médios } \\
\cline { 2 - 5 } & $\mathrm{CC}(84 \mathrm{DAE})$ & $\mathrm{DC}(84 \mathrm{DAE})$ & $\mathrm{CV}(84 \mathrm{DAE})$ & $\mathrm{LV}(84 \mathrm{DAE})$ \\
\hline Irrigação & $0,37^{*}$ & $0,31^{*}$ & $0,29^{*}$ & $0,10^{*}$ \\
Regressão Linear & $1,30^{*}$ & $1,16^{*}$ & $0,68^{*}$ & $0,32^{*}$ \\
Regressão Quadrática & $0,01^{\mathrm{ns}}$ & $0,07^{\mathrm{ns}}$ & $0,35^{*}$ & $0,03^{\mathrm{ns}}$ \\
Desvio Regressão & $0,09^{\mathrm{ns}}$ & $0,00^{\mathrm{ns}}$ & $5,26^{* *}$ & $0,03^{\mathrm{ns}}$ \\
Bloco & $0,03^{\mathrm{ns}}$ & $0,01^{\mathrm{ns}}$ & $0,07^{* *}$ & $0,04^{* *}$ \\
CV $(\%)$ & 4,31 & 2,15 & 1,19 & 1,17 \\
\hline
\end{tabular}

${ }^{*}$ Significância a $1 \%$ pelo teste $\mathrm{F} .{ }^{* *}$ Significância a $5 \%$ pelo teste $\mathrm{F}$. ns não significativo pelo teste $\mathrm{F}$ ao nível de $5 \%$.
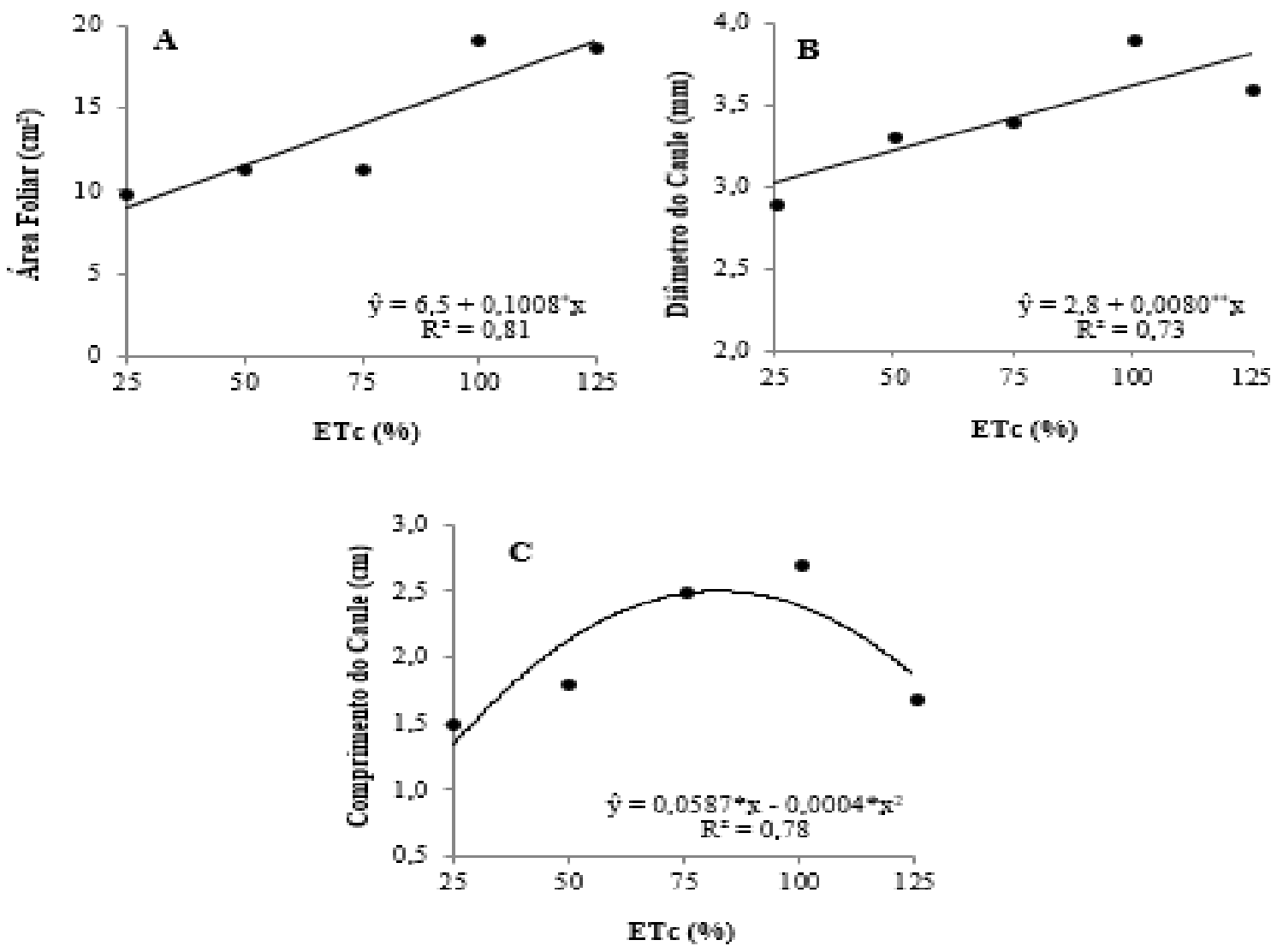

* Significância a $1 \% .{ }^{* *}$ Significância a $5 \%$.

Figura 1 Área foliar (A), diâmetro do caule (B) e comprimento do caule (C), ao $10^{\circ}$ dia após a semeadura de feijão comum, em função da evapotranspiração da cultura (ETc). 

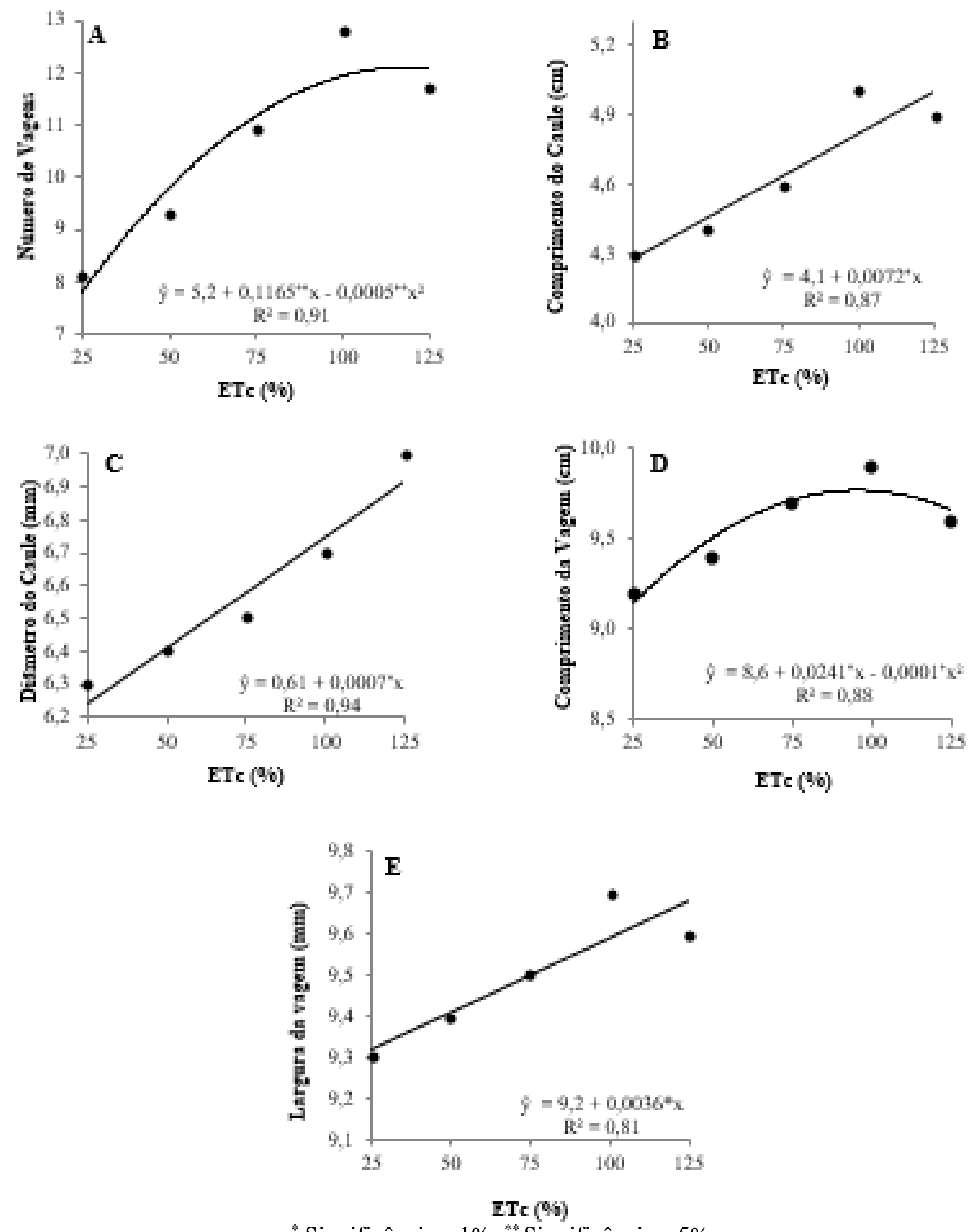

* Significância a $1 \%$. ${ }^{* *}$ Significância a $5 \%$.

Figura 2 Número de vagens por planta (A), comprimento do caule (B), diâmetro do caule (C), comprimento da vagem (D) e largura da vagem (E) de Phaseolus vulgaris aos 84 dias após a semeadura, em função da evapotranspiração da cultura (ETc).

Assim como a área foliar, o diâmetro do caule aumentou proporcionalmente às lâminas de águas aplicadas, sendo que o maior diâmetro foi observado nas plântulas que receberam $100 \%$ da ETc (Figura 1B). Já o comprimento do caule foi teve o melhor ajuste quadrático e a partir da 
derivada da equação de regressão verifica-se que a eficiência máxima para esta variável foi obtida ao utilizar uma lâmina de $73 \%$ da ETc (Figura 1C).

Estudar a morfologia do feijoeiro em várias condições de disponibilidade hídrica implica no reconhecimento do padrão de crescimento e desenvolvimento da cultura, o que favorece na tomada de decisão quanto à quantidade de água que deve ser disponibilizada para planta. Em vista disso, o produtor evita o uso irracional da água e passa a produzir de forma sustentável, já que a disponibilidade de água para a irrigação será reduzida no futuro, devido ao aumento da demanda por outros setores prioritários (SANTOS et al., 2010).

No final do ciclo observou-se que o maior número de vagem por planta foi obtido quando foram aplicadas as maiores lâminas de água, com a eficiência sob a lâmina de $1175 \%$ de água em relação à ETc (Figura 2A). Assim, percebeu-se que o déficit hídrico ocorrido pela aplicação das menores lâminas influenciou negativamente o número de vagens na planta. Para Guimarães et al. (2011), o número de vagens por planta é o componente agronômico mais sensível ao estado hídrico do feijoeiro comum, o que ressalta a importância de contabilizar tal vagens quando seu almeja uma produção satisfatória.

O comprimento do caule aumentou de forma linear proporcionalmente à aplicação de água, desse modo, tal aumento foi de $0,0072 \mathrm{~cm}$ para cada $1 \%$ de ETc (Figura 2B) e o diâmetro do caule respondeu favoravelmente às maiores lâminas aplicadas (Figura 2C). O comprimento da vagem (Figura 2D) teve eficiência máxima quando as plântulas do feijoeiro receberam a aplicação de $121 \%$ de água. Entretanto, a largura da vagem respondeu satisfatoriamente até a lâmina de $100 \%$ da ETc, uma vez que na lâmina de $125 \%$ da ETc houve uma redução da largura (2E).

Resultados semelhantes foram encontrados por Oliveira et al. (2011), no qual verificou que a menor lâmina de irrigação aplicada reduziu parâmetros do crescimento na cultura estudada, assim como Costa et al. (1997), Leite e Virgens Filho (2004) constataram que as reduções nos parâmetros de crescimento estudados foram de $56 \%$ e $61 \%$, respectivamente, quando o estresse hídrico foi imposto na fase reprodutiva.

\section{Conclusão}

Os níveis de irrigação inferiores a 100\% da evapotranspiração da cultura afetaram negativamente as variáveis analisadas, uma vez que inibiu o crescimento, com maior intensidade na área foliar e no número de vagem.

\section{Referências}

ARAÚJO, R. S. et al. Cultura do feijoeiro comum no Brasil. Piracicaba: Associação Brasileira para Pesquisa de Potassa e do Fosfato, 1996. 786p.

CARVALHO, G. J. et al. Correlação da produtividade do feijão com a resistência à penetração do solo sob plantio direto. Revista Brasileira de Engenharia Agrícola Ambiental, v. 10, n. 3, p. 765-771, 2006.

COSTA, M. M. M. N. et al. Produção, componentes de produção, crescimento e distribuição das raízes de caupi submetido à deficiência hídrica. Pesquisa Agropecuária Brasileira, v. 2, n. 1, p. 43-50, 1997.

DOORENBOS, J.; KASSAN, A. H. Crop response to water. Roma: FAO, 1979. 194p. (Irrigation and Drainage Paper, 33).

EMPRESA BRASILEIRA DE PESQUISA AGROPECUÁRIA - EMBRAPA. Centro Nacional de Pesquisa de Solos. Sistema brasileiro de classificação de solos. 2.ed. Rio de Janeiro, 2006. 306p.

FERNANDES, F. B. P. et al. Efeito de manejos do solo no déficit hídrico, trocas gasosas e rendimento do feijão-de-corda no semiárido. Revista Ciência Agronômica, v. 46, n. 3, p. 506-515, 2015.

FERREIRA, D. F. Sisvar: a Guide for its Bootstrap procedures in multiple comparisons. Ciência e Agrotecnologia, v. 38, p. 109-112, 2014.

FREITAS, C. A. S. et al. Comportamento de cultivares de mamona em níveis de irrigação por gotejamento em Pentecoste, CE. Revista Brasileira de Engenharia Agrícola e Ambiental, v. 14, n. 10, p. 1059-1066, 2010.

GUIMARÃES, C. M. et al. Genótipos de feijoeiro comum sob deficiência hídrica. Revista Brasileira de Engenharia Agrícola e Ambiental, v. 15, n. 7, p. 649-656, 2011. 
GUIMARÃES, C. M.; STONE， L. F.; ORIVALDO, B. Adaptação do feijoeiro (Phaseolus vulgaris L.) à seca. Revista Agropecuária Brasileira, v. 311, n. 7, p. 481488, 1996.

LEITE, M. de L.; VIRGENS FILHO, J. S. das. Produção de matéria seca em plantas de caupi (Vigna unguiculata (L.) Walp) submetidas a déficits hídricos. Publicatio UEPG Ciências Exatas e da Terra, Ciências Agrárias e Engenharias, v. 10, n. 1, p. 43-51, 2004.

MANOS, M. G. L.; OLIVEIRA, M. G. C.; MARTINS, C.R. Informações Técnicas para o Cultivo do Feijoeiro Comum na Região Nordeste Brasileira 2012-2014. Aracaju: Embrapa Tabuleiros Costeiros, 2013. 199 p.

MARTINS, M. et al. Avaliação de genótipos de feijoeiro comum do grupo comercial carioca cultivados nas épocas das águas e do inverno em Uberlândia, Estado de Minas Gerais. Acta Scientiarum. Agronomy, v. 31, n. 1, p. 2328, 2009.

MENDES, R. M. S. et al. Relações fonte-dreno em feijão-de-corda submetido à deficiência hídrica. Revista Ciência Agronômica, v. 38, n. 1, p. 95-103, 2007.

OLIVEIRA, G. A. et al. Resposta do feijão-caupi as lâminas de irrigação e as doses de fósforo no cerrado de Roraima. Revista Ciência Agronômica, v. 42, n. 4, p. 872-882, 2011.

PAULA JÚNIOR, T. J. et al. Informações Técnicas para o cultivo do feijoeiro-comum na região central brasileira: 2007-2009. Viçosa: Epamig, 2008.

PEIXOTO, C. P. Curso de Fisiologia Vegetal. Cruz das Almas: Universidade Federal do Recôncavo da Bahia, 2011. 177 p.

PEREIRA, A. R. et al. Evapotranspiração. In: PEREIRA, A. R.; ANGELOCCI, L. R.; SENTELHAS, P. C. Agrometeorologia: Fundamentos e aplicações práticas. Guaíbal; Agropecuária, 2002. 213p.

SANTOS, C. et al. Performance of an irrigation scheme using indicators determined with remote sensing techniques. Irrigation Science, n. 28, p. 461-477, 2010.
SANTOS, M. G. et al. Photosynthetic parameters and leaf water potential of five common beans genotypes under mild water deficit. Biologic Plantarum, v. 53, n. 2, p. 229-236, 2009.

SILVA, C. D. S. e et al. Curso diário das trocas gasosas em plantas de feijão-caupi submetidas à deficiência hídrica. Revista Caatinga, v. 23, n. 4, p. 7-13, 2010.

SILVA, M. C. C. et al. Soil physical attributes and yield of winter common bean crop under a notill system in the brazilian Cerrado. Revista Caatinga, v. 30. n. 1, p. 155-163, 2017.

SILVEIRA, P. M. DA; STONE, L. F. Manejo da irrigação do feijoeiro: uso do tensiômetro e avaliação do desempenho do pivô central. Brasília: EMBRAPA-SPI, 1994. 46p.

SIMPLÍCIO, S. F. et al. Características de crescimento e produção do feijão-caupi (Vigna unguiculata L. Walp.) sob aplicação de herbicidas. Agropecuária Técnica, v. 37, n. 1, p. 55-62, 2016.

SOARES, W. R. et al. Dependência do coeficiente de cultura no estádio inicial de desenvolvimento (Kc ini) à lâmina de irrigação e textura do solo. Revista Brasileira de Engenharia Agrícola e Ambiental, v. 5, n. 1, p. 23-27, 2001.

SOUSA, A. E. C. et al. Produtividade do meloeiro sob lâmina de irrigação e adubação potássica. Engenharia Agrícola, v. 30, n. 2, p. 271-278, 2010.

TAIZ, L.; ZEIGER, E. Fisiologia vegetal. 5.ed. Porto Alegre: ARTMED. 2013. 954p.

TURCO, J. E. P., RIZZATTI, G. S.; PAVANI, L. C. Custo de energia elétrica em cultura do feijoeiro irrigado por pivô central, afetado pelo manejo da irrigação e sistemas de cultivo. Engenharia Agrícola, v. 29, n. 2, p. 311-320, 2009.

VALADÃO, L. T., KLAR, A. E. Evapotranspiração do feijoeiro comum (Phaseolus vulgaris L.), em dois níveis do lençol freático. In: CONGRESSO NACIONAL DE IRRIGAÇÃO E DRENAGEM, 11., 1996, Campinas. Anais...Campinas: Associação Brasileira de Irrigação e Drenagem, 1996. v. 1, p.163-176. 